\title{
Climate Change and Public Moral Reasoning
}

\author{
Jonathan Webber
}

\author{
To appear in New Waves in Ethics, edited by Thom Brooks (Palgrave, 2011) \\ Penultimate draft. Please cite only final version.
}

Climate change could well be the most significant moral challenge people ever face. We now know that carbon dioxide, methane, and other gases generated by our industrial, agricultural, and personal activities are changing the balance of the atmosphere, trapping more of the sun's heat and raising average global temperatures. We know that as the oceans warm up and the polar ice caps melt into them, sea levels will rise. This rise will not only cause severe flooding around the world, but in concert with the rising temperature it will have a profound effect on the weather system. Hurricanes and storms will become more powerful. Rainfall patterns will change, turning currently verdant lands into deserts and causing further flooding elsewhere. Some rivers and lakes will dry up, others will overflow. Heatwaves will strike more places more frequently and more intensely. We know that a certain amount of all this is inevitable. Indeed, it seems already to have begun. Because the oceans heat up slowly, absorbing some of the excess temperature in the atmosphere, there is a significant time lag between the emission of greenhouse gases into the atmosphere and the climatic problems caused by those gases. Past emissions are wholly responsible for the changes we will see over the next couple of decades. Our actions now will have no impact on the climate for twenty to thirty years; the shadow they then cast will be decades long. (For a careful explanation of all of this, see Walker and King 2008: part 1.) 
This will have a tremendous effect on humanity. There will be unprecedented numbers of lives lost in storms, floods, heatwaves, and droughts. But such events are only part of the problem. Diseases will be relocated from the parts of the world where they are long established, and where some degree of local immunity has developed, to new and therefore more vulnerable populations. Inhabited lands will become uninhabitable as drought becomes permanent, or their land and water no longer yield food, or they become too frequently flooded for it to be worth rebuilding each time. We should expect to see mass starvation, mass displacement of people, and wars fought over access to water and fertile land. The ongoing conflict in Darfur, for example, seems to have been triggered by the food and water shortages caused by sustained drought, itself a result of a change in air currents brought about by a change in the relative temperatures of the northern and southern parts of the Atlantic Ocean, which may in turn be the result of greenhouse gas emission (Walker and King 2008: 47-8). Whether or not greenhouse gases triggered that particular war, it is clear that emissions are likely to have such effects.

We are inadvertently changing the atmosphere in a way that will have devastating effects on people all over the world. The extinction of the human race is a possible outcome of this, but a remote one. Between here and there lies immense suffering. What is more, we now know this. We are now burdened with knowledge of which our polluting forebears were blissfully ignorant.

One set of moral questions raised by these facts concerns mitigation of the effects of climate change that is already inevitable. Since the Western world has benefitted most from the activities that have involved the emission of greenhouse gases over the past couple of centuries, and most intensely over the past few decades, and since anyway the richer part of the world is best equipped to help alleviate the problems of climate change, what impact should consideration of climate change have on our immigration policies, our world trade policies, and our overseas aid and development projects? A second set concerns the rightful distribution of further emissions, given the disparity between countries in economic development so far and the correlation between that disparity and greenhouse gas emissions past and present. As well as being 
moral questions, these are pressing political concerns that are likely to be the subject of much academic and popular discussion over the next decade and more.

There is a further set of issues, however, that also needs to be addressed, one that politicians hoping to be re-elected are understandably reticent about. These are issues of personal behaviour. But that is not to say that they are a purely personal matter: they are also a matter for public policy. What impact should our knowledge of the implications of greenhouse gas emission have on the behaviour of individuals? What difference should it make to our goals and aspirations? What is the role of the state in regulating this? In short: how should we live, given what we know?

Recent discussion in this area, both academic and popular, has tended to focus on intergenerational justice and the question of how we should factor people of the future into our moral reasoning. These are indeed important theoretical questions (see e.g. Kavka 1982; Parfit 1982; Mulgan 2006). That they are so prominent among popular treatments of the issue, on the other hand, might rather be because apocalyptic future scenarios have always made good box office. But the problem is really more urgent than might be clear from such discussions. A child born in the UK in 2010 has an average life expectancy of 80 years. By the time these people have reached maturity, become independent of their parents, and are thinking seriously about whether to bring children of their own into the world, our greenhouse gas emissions will already be affecting their climate and their international political situation. We will continue to have such an effect, indeed increasingly so, for the remaining half century of their lives. Swaziland has the lowest life expectancy at birth in 2010, according to the CIA World Factbook, but at 40 years this is still longer than the time it will take for our emissions to affect their climate. The global average life expectancy at birth in 2010 is 67 years. Our greenhouse gases will thus affect the lives of hundreds of millions of people already alive around the world.

The moral dimension of climate change is not simply about the possibility of catastrophic events way off into the distant future. It is about our causing a grave cumulative deterioration of the physical and social 
world across the lifetimes of people already here. Thinking seriously about this problem requires its public presentation to emphasise this nearer future as well as the distant future. But it also requires a change in the nature of public moral reasoning itself, as we will see; a change that will bring public moral discourse closer to academic moral philosophy, though the academic discussion too needs to develop in an important way.

\section{II}

What is required, however, is not the proposed alteration to moral reasoning that has dominated academic environmental ethics for the last forty years. That proposal has been that our existing value system needs to be changed fundamentally in order to accommodate the intrinsic value of nature (e.g. Routley 1973; Rolston 1975; Lee 1994). The very idea of a fundamental change of moral values seems practically and philosophically problematic. In practice, the claim allows people to reject any concern for the environment at all. Consider as a parallel the religious values of holiness and grace, with their antitheses of profanity and sin. If these are not already part of your valuational scheme, then you will not be moved when someone describes some aspect of your behaviour as profane or sinful. These are part of a religious outlook that is foreign to you. If that someone then argues that you ought to share this religious outlook because otherwise you will remain in a state of sin, you can cheerfully ignore this as just more empty terminology of a mistaken worldview. Unless it can be shown that the values you already hold commit you to rejecting the state of sin, you will not be moved by any argument for rejecting it. Public moral reasoning proclaiming that we should all adopt a wholly new value, one to which we are not already committed by our existing values, therefore, seems to backfire. Not only does it fail to engage policy makers and the public at large, as Andrew Light (2002: 435-41) has argued; it positively encourages the belief that concern for the environment is simply a specialist interest or minority pursuit.

This is not only a point about the rhetoric of public reasoning. For it seems not only that disconnecting 
environmental concern from existing values in this way is apt to cultivate a lack of interest in the environment, but moreover that such a lack of interest would indeed be the correct response, just as it is the correct response of a nonbeliever to threats of an eternity in hell. The issue is not only what will in fact motivate people, but also what would justify that motivation. If an argument for valuing something is to gain any rational traction, it must appeal to our existing values. Not just any kind of appeal will do. Consider, for example, the attempt to convert nonreligious people to religious belief by arguing that without a religious outlook one cannot be committed to moral value. A nonbeliever who accepted the claim at the heart of this argument could respond in either of two ways. One would be to abandon morality altogether, on grounds that it is no more warranted than the values of holiness or grace. But the argument has been presented on the assumption that the nonbeliever will not respond in this way. The argument assumes, that is to say, that the nonbeliever will go in the other direction: that having good reason to retain their moral values, they will have to accept a religious outlook. But this is precisely what makes the argument mistaken. If the nonbeliever already has good reason to retain their moral commitments, before they have converted to religious belief, then religious belief is not required as warrant for those commitments. Although nonbelievers might be disconcerted by the claim about morality, therefore, this very fact shows that they ought not to be (compare Lenman 1999: esp. \8).

Conversion to a religious outlook, therefore, cannot be rationally warranted by a nonbeliever's commitment to morality in conjunction with the claim that such moral values presuppose religion, for the first of these conjuncts shows the second to be false. What would be required is an argument that goes in the other direction, one aimed at showing that religious values are specifications of our deeper moral values as these are applied to some aspect of life. Were such an argument to be made out successfully, it would indeed show that the nonbeliever's morality entails a religious outlook. It would show that our moral values ground religious ones, rather than the other way around. Likewise, the claim that we should come to value the natural environment could not be justified except by showing the requisite value to be grounded in our existing moral values in this way. 
The idea that proper concern for the environment requires a change in our fundamental values is thus rather curious. What could be offered to try to justify or even motivate such a claim? The standard argument for it involves a thought experiment: if the last person alive wantonly damages the environment in their dying moments, have they done wrong? Proponents of the intrinsic value of nature argue that the

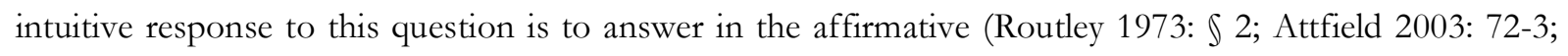
Jamieson 2007: $₫ 21)$. This very strategy seems to contradict the idea that we need to change the basis of our value system, for our response to the thought experiment surely reflects our existing values. To avoid this contradiction, the argument would have to be construed as showing that our values are inconsistent if we deny the intrinsic value of nature. Such an inconsistency could equally well be averted, however, by rejecting the claim that this action by the last person alive would be wrong.

One way in which we could reject that claim would be to show that the judgment that one ought not damage the environment is generally right but mistaken in the last person scenario. This argument could be based on a naturalistic account of our respect for nature, one that finds the scope and justification of that respect in the explanation of its origins and psychological role. Although he does not deploy his account for this purpose, one good example of such an analysis is provided by Bernard Williams when he argues that there is a respect for nature already built into our valuational system, a respect with deep historical roots in the fear of nature as an unpredictable adversary as well as a provider. Williams counsels caution in considering this aspect of our valuational system, since it is 'a value which we have good reason, in terms of our sense of what is worthwhile in human life, to preserve, and to follow, to the extent that we can, in our dealings with nature' (1995: 239). Our respect for nature, on this account, is justified by its place in the weave of our valuational fabric as a specification of other values in the context of dealing with nature and perhaps as helping to ground further values. Since the last person scenario excludes anything other than nature that we might care about, including our own survival and that of our kin and species, the condemnation of the last person's act of vandalism looks to be an expression of this respect in a context in which it is not justified. 


\section{III}

Were we somehow to come to see the natural environment as intrinsically valuable rather than as deriving its value from our other concerns, moreover, then it seems that we should not care at all about the changes that nature is undergoing. As is often pointed out, the climate changes of its own accord. Why should climate change resulting from our activity be morally important? We are part of the natural system in which we live, as many environmentalists remind us, so the climate change we generate is just part of the overall process of the biosphere. If nature itself is ultimately valuable, why should we care about any particular configuration of nature? Should we not rather just continue to let nature take its course? If we hold this intrinsic value of nature to be less important than the value of humanity, of course, then we should ensure an environmental configuration that is good for human survival and well-being. But in this case, our environmental ethics is resting entirely on the value of humanity and the purported independent value of nature is redundant (compare Crisp 1994: \12). Either the value of nature is as an instrument for our purposes, that is to say, or it cannot ground any moral constraints on the way we affect the environment.

One might try to avoid this dilemma by arguing that what is valuable in nature is the abundance and diversity of living things (and perhaps non-living things too). We should preserve natural multiplicity, on this view, and since the environmental conditions required for that are the same as those required for human survival and flourishing we will thereby maintain an environment fit for humans. Since the benefit to humanity here is incidental to our primary concern, the value of humanity would be subordinate to that of nature. This is not to say that humanity would be of no value. We may value humanity alongside our concern for natural diversity. But where the two values conflict, natural diversity must take precedence if this is not to be a mere secondary supplement to valuing nature as a means to human ends.

In subordinating humans to natural diversity in this way, however, it seems that we have not accorded humanity its proper value. The normative theories that dominate moral philosophy agree that our status as 
rational animals earns us a greater value than that due to the rest of nature, whether this is because of the respect due to reflective self-direction and responsibility or because rational anticipation and decision affords the opportunity of happiness or flourishing greater in kind or degree than can be available otherwise. The very fact of this agreement across deeply divergent understandings of morality seems to reflect something fundamental to our outlook, which would explain why concern for the interests of other people seems a minimal requirement of morality. Our value system, therefore, should not, indeed cannot, allow us to subordinate the value of people to that of the environment when the two conflict. The rest of nature must be subordinate to the interests of people. We should value the rest of nature, therefore, primarily as the theatre of human agency. If we do not value it in this way, then we do not give humanity its due. For if we do not care about the theatre of human agency, then we have no reason not to allow it to deteriorate in a way that we know will have severely detrimental effects on people over the next century and beyond. On the other hand, we are morally obliged not to accord the nature that makes up that theatre a value above that of the people who act in it.

It is not the environment that we should value, then, but our environment, the context of our endeavours. The value of the nature that makes up this context is not intrinsic. It is valuable only on condition that it is a context of human agency. The value of this context, moreover, is not just as a setting in which our purposes are pursued, but as a setting that is structured in such a way as to afford the pursuit of those purposes. In this sense, its value is instrumental. This is not equivalent to saying that the world should be treated as a set of resources to be used for whatever ends anyone wants to pursue. Neither is it to say that the environment is ours to exploit for immediate economic gain. If we treat the world in that way, then we can expect climate change to accelerate and our environment to cease to function as an instrumental context for our purposes. That would be to fail to respect the value nature has. It is because nature is valuable as an instrumental context for our purposes that we should strive to maintain a configuration of nature that continues to suit human purposes. The challenge of climate change does not require us to adopt any fundamentally new value, even if such a value could be motivated and justified; we need only recognise the importance of our environment for what we already value. 
This is not to deny, however, that the natural world is intrinsically valuable. On this account, all the value of the world is wholly contained within the world. For we are part of the world. The value of the world is not relative to anything unnatural or supernatural. But it does consist in the value of humanity and the consequent value of the instrumental context of humanity. So although the value of our environment is extrinsic, since it is relative to us, the value of the world as a whole is nevertheless intrinsic. (Incidentally, this seems to me to be precisely what Aldo Leopold is arguing in 'The Land Ethic' (1949), an essay widely cited as the progenitor of recent arguments for embracing the intrinsic value of our natural environment.) These rather technical thoughts about the intrinsic value of the world, however, have nothing to contribute to public moral reasoning about, as opposed to academic clarification of, the moral challenge of climate change. Public discussion would do best to focus on the value of humanity and the importance of our environment in relation to that value (as does, for example, Garvey 2008).

\section{IV}

What does need to change is the understanding of human desire and behaviour that informs public discussion of strategies for reducing greenhouse gas emissions. The emphasis is currently on developing techniques for increasing the efficiency with which we generate power, produce food, and travel around. There is little appetite for serious consideration of how we might change our goals and priorities in ways that reduce our demand for the things that are causing the problem. It seems generally assumed that such demand will remain. One popular book on the topic, for example, coauthored by a former chief scientific adviser to the UK government, is subtitled 'How To Tackle Global Warming And Still Keep The Lights On' (Walker and King 2008). Mainstream debate about responding to climate change is thereby dominated by such issues as whether we should invest in controversial nuclear or carbon-capture energyproduction technologies, the extent to which we should build wind farms and where they should be sited, whether we can expand our airport capacity, and which cities should be linked by a few high-speed rail 
lines.

Increased efficiency is clearly an important part of the solution. But if the aim is to allow individuals in high-emission countries to reduce emissions while retaining their lifestyles, then this strategy will not tackle the overall problem. For rising prosperity around the world is rapidly increasing the number of people with access to such lifestyles. Unless severe limits are imposed on this increase, global greenhouse gas emissions will continue to rise even as per capita emissions of the wealthiest fall. There would seem to be neither power nor legitimate authority to impose such limits on people aspiring to the lifestyles to which part of the world are already accustomed.

A minority voice in the climate change debate is therefore arguing that it is morally incumbent on people in the affluent parts of the world to change their lifestyles. While the mainstream view involves asking people to choose energy efficient lightbulbs and appliances, the minority argue that we should go much further: we should give up altogether on such unsustainable luxuries as air travel and private cars, and since individual asceticism will not be enough we should campaign for such restrictions to be imposed by government. These writers seem to agree with their opponents that such changes would be felt as deprivations. 'Doing something about climate change is probably considerably more demanding than minor life-changes', writes James Garvey; we ought to 'tighten our belts and cut back on our easy lives of high-energy expenditure' (2008: 145, 156). George Monbiot describes 'the campaign against climate change' as 'a campaign not for abundance but for austerity' (Monbiot 2007: 82). The campaign to slash consumption of greenhouse gases is 'a campaign not just against other people, but also against ourselves' (Monbiot 2007: 312), or simply 'by us, against us’ (Garvey 2008: 152).

Common to the mainstream and minority outlooks, therefore, is a tacit acceptance that the current level of greenhouse gas emission by the affluent portion of humanity is just a natural result of unfettered or unregulated pursuit of our desires. This picture of human motivation and behaviour seems to be behind political reticence around the idea of limiting climate change by altering our lifestyles. Since politicians 
need to be re-elected, they would indeed be ill advised to constrain the voters' pursuit of their desires in ways that do not directly and immediately benefit substantial numbers of voters. The same picture lies behind Monbiot's diagnosis of hypocrisy among environmentalists themselves, which he illustrates with anecdotes of heated garden greenhouses and private jets, concluding that 'we consume as much as our incomes allow' (2007: 24). It is this picture that leads him to his pessimistic prognosis: 'nobody ever rioted for austerity' (2007: 312).

Yet surface human desires are not simply hard-wired. They are manifestations of deeper motivations within an ambit circumscribed by available opportunities and their relative costs, associations enshrined in culture and marketing, and the social and political decisions of our forebears that have established these. It would seem, therefore, that altering the ambit within which we make our everyday decisions would alter the decisions we are likely to make. Rather than deny ourselves the things that we want, we could manipulate the social world in such a way that we want different things. This is not to suggest a deep reprogramming of our desires or values. Quite the opposite: it is to suggest that the ways in which those are played out is to a large extent a contingent matter of the way history and economic power have structured the realm in which they are played out, a contingent matter that can easily be altered. Monbiot himself actually provides a very good example of this. Most of us now buy our food from supermarkets that consume huge amounts of energy to power fridges that keep produce cold and heaters that keep customers warm as they pick produce from those fridges. Most of us then take the goods home in large private cars that are only a little less empty than they were on arrival. Monbiot points out that there would be massive energy savings to be made in converting these supermarkets into warehouses from which consumers could place orders for home delivery (2007: 281-9).

Why should this be thought of as an austerity measure? Can it really be true that the majority of the electorate enjoy the supermarket shopping experience? Monbiot agrees that this seems unlikely (2007: 289-90). So if we enacted this idea, we would not be denying ourselves anything that we value or even want. We currently shop that way simply because that is the food distribution system we find ourselves 
living with. What is more, this kind of energy saving need not require government to impose restrictions on the behaviour of its citizens. Monbiot suggests that there are only two ways in which supermarkets could become home delivery warehouses: through direct government regulation of their activities; or through the consumer pressure that would be generated if each consumer had only a limited ration of greenhouse gas emission per year (2007: 289). But this seems mistaken. There are many other incentives that governments could offer to supermarkets and to consumers, not least through taxation. Simply changing the framework within which people make their decisions, therefore, can change their behaviour in ways that would make a very significant contribution to the reduction of greenhouse gas emissions. This need not involve asceticism or austerity; it could even improve our quality of life.

Once we see how this might work, similar thoughts arise about other aspects of the affluent world's lifestyles. Are regular long-haul flights to exotic and photogenic locations, for example, really the natural expression of our inherent curiosity and wanderlust? Or are they simply the product of pervasive marketing over the last few decades? Would our deeper desires perhaps be better served by nearer places with which we could engage in a more sustained and sophisticated way? Similarly, do mass-produced bottled lagers outsell local cask ales because drinkers have some deep natural preference for them? If so, why all the advertising? On a larger scale, why do we spend most evenings each in our own homes cooking our own meals and using our own entertainment systems? Is it because of a natural desire for seclusion? Or is it to some extent because our current economic and social opportunity structures make this the best way to eat and relax? To what extent could fiscal reform reduce greenhouse gas emissions by promoting a massive increase in the amount of communal eating and entertainment? There are economies of scale in energy consumption just as there are in the production and distribution of goods. Why would any voter think of increased access to restaurants, cinemas, concerts, and so forth as a hardship?

These are not offered as considered proposals. The point is rather that creative thinking about reducing energy consumption is severely hampered by the apparently shared assumption that our current lifestyles simply reflect our natural desires. Were this assumption correct, then the only strategy available would be 
to reduce as far as possible the greenhouse gas emissions generated by the pursuit of those desires. But as these examples indicate, it is far from clear that the assumption is correct. It rather seems that the right kind of alterations to the social world in which we deliberate, choose, and act would allow us to cut emissions dramatically while getting as much or even more of what we want and care about. What needs to change in public moral reasoning is not the values employed but the understanding of human psychology that frames their employment.

Part of the reason for the shared assumption, it seems, is that environmentalism has long been associated with the idea that our lives have become alienated from our natural home, that we should aim to live in much closer contact with the natural world than our industrial, consumerist, urban existence allows. There is persisting image of environmentalists as luddites knitting their own jumpers out of leftover wholewheat muesli in cold yurts on drizzly hillsides. This image may well be informed by the talk of the intrinsic value of the natural world that has featured so prominently in moral reasoning about the environment over the past few decades, though it is also worth noting that portraying proponents of change in an unattractive light serves the interests of those whose economic and cultural power rests on maintaining the status quo. If the campaign against climate change is to have any hope of success, it needs to break the association with that image. Not only would this be expedient, it would also be right. For the reason to make drastic reductions in our greenhouse gas emissions is not grounded in the value of our natural environment but in the value of humanity ourselves, and strategies for doing so need not require abstinence or austerity.

Public moral reasoning about climate change would do well to focus, therefore, on low-emission strategies for human fulfilment given our existing values and deep desires. Combined with technological means of reducing the greenhouse gas emissions involved in these activities, such strategies could maintain or even increase our enjoyment and well-being while giving due respect to the interests of the people who will be 
alive in a few decades time. This would not be a campaign against our own interests. It need not promote unpopular lifestyle changes. But this is not to say that it would be free of opposition. For the individuals and corporations who profit from the current social and economic structures are likely to campaign against change, through political lobbying of the kind that has already significantly impeded emission reduction strategies (see e.g. Monbiot 2007: 112-6, 126), but also through promoting in the culture generally negative images of change and positive images of the status quo. There would seem to be ample opportunity for profit to be made from proposed new ways of doing things, however, so this aspect of the campaign against climate change need not be without allies in buisness. Success depends ultimately on promoting strategies likely to appeal to a critical mass of people as well as to businesses prepared to enact them.

Central to such a campaign would be inquiry into the relevant aspects of psychology and their bearing on proposed alterations to the way that we live. Discussion of alterations to our social structures should be informed by an understanding of the nature of our deep desires and values and the relations between these and our more immediate motivations in everyday action. Without this understanding there can be no serious attempt to preserve or enhance the quality of our lives while altering the social framework within which we decide and act. To some extent, this is a recommendation that public moral reasoning about climate change move closer to academic moral philosophy. For academic ethics has long included reflection on the nature of our values and motivations. Some of the most sophisticated discussion of the value we find in the natural environment is of this kind (e.g. Crisp 1994; Williams 1995). But this recommendation also requires a development in the mainstream academic understanding of moral thought. For the kind of moral inquiry recommended here does not fit neatly into that understanding.

It might seem otherwise, since it might seem that the approach recommended here is a form of virtue consequentialism according to which we ought to develop certain character traits rather than others in order to ensure the best consequences of our actions for the environment in which people will live (e.g. Jamieson 2007). But the present argument is intended neither to endorse consequentialism nor to 
proclaim that we should cultivate virtuous character traits. It is intended to hold independently of the debate over whether good consequences, right actions, or virtuous character traits have normative priority within morality. For it seems that no satisfactory theory of morality could allow us to knowingly cause such a severe deterioration of the social and physical environment in which hundreds of millions of the people around us will live out their lives when we could do otherwise at little significant cost to ourselves. Concern for the interests of other people does seem, as mentioned earlier, a minimal criterion of morality. What is more, the argument given here is intended to show that we can change our behaviour in ways that will significantly reduce our own greenhouse gas emissions and provide a model low-emission lifestyle for the billions of people aspiring to our level of wealth without making any important change to our values or desires; it is not a matter, then, of developing the right character at all.

\section{VI}

The possibility of the approach to climate change recommended here is obscured by the image of moral philosophy that currently dominates academic ethical discussion, according to which there are three tiers of ethical theory. At ground level, 'applied ethics' is discussion of the moral dimensions of actual practices such as euthanasia, torture, or prostitution. The second tier is 'normative ethics', the discussion of whether morality is fundamentally concerned with consequences, actions, intentions, or character traits, and consequently of what determines the content of moral requirements. The top tier is 'metaethics', which is concerned with the metaphysical, epistemological, and psychological aspects of normative ethics. Whether moral values exist independently of ourselves, for example, how we can come to discover the nature of morality, and how moral norms are connected with human motivation are all metaethical questions. This framework is usually understood as a kind of hierarchy in which discussion at ground level is constrained by the tier of normative ethics, which in turn is constrained by the tier of metaethics. If contextindependent moral principles must be rejected on metaethical grounds, for example, then they can form no part of normative ethical theory, in which case no context-independent normative moral principle can 
be applied to any moral issue. Although this structure is not wholly agreed by all moral philosophers, it is fair to say that it dominates current academic ethical theory.

Within this structure, the discussion of moral psychology is contained within the tier of metaethics. The only discussion of psychology that can fit within the structure, that is to say, is discussion of the psychological aspects of normative ethical theories. A range of normative theories enjoin us to develop such virtues as courage, honesty, or generosity, for example, which in turn means that the psychological possibility and structure of such virtues is an issue within the tier of metaethics. But the discussion of character traits more generally does not find any home within this structure. For if virtues and vices are distinguished in some structural way from other character traits, then the discussion of character traits will not pertain with sufficient precision to normative theories enjoining virtue; and if there is no such structural difference then it seems that nothing can be lost to metaethics by focusing on virtues and vices themselves rather than character traits. This is not to say that character is not an interesting philosophical issue. Philosophers interested in virtue have argued that we do need to consider the psychology of character if we are to assess the actual psychological viability of virtue ethics. But the debate they have generated has involved some crucial misunderstandings where claims about character have been read as though they are claims about virtue (see Webber forthcoming). This confusion is well explained by the prevalence of the three-tier model of ethics, which gives the concept of virtue a central place in moral philosophy but denies a place to character.

A similar problem is generated by the three-tier model for the kind of applied moral psychology advocated in this chapter. Although discussion of the way in which the expression of desire and value in action is shaped by the social world would be relevant to any normative theories that combine concern for good consequences with the idea that decisions are determined by situations (e.g. Doris 2002: ch. 7), such theories are only minor players in overall normative ethical debate. A more general discussion not tied to any particular normative theory seems not to fit within metaethics. Investigation of this issue is therefore likely to be hampered in the same way as discussion of the nature of character has been: descriptive claims 
may well be taken for normative ones, or be recognised as descriptive and thereby dismissed as not relevant to ethics. We ought not to accept this dismissal, however, since to do so is to impoverish our applied ethical theorising. Aspects of human psychology that do not feature in any major normative theory can usefully be brought to bear directly on moral issues. Indeed, some moral issues cannot be properly addressed otherwise.

This chapter is intended to show that in the absence of an understanding of the way in which our immediate motivations are generated by deeper desires and values within the constraints of the social environment, moral thought about climate change is blinkered in such a way that some of the most promising and creative responses will simply not be seen. This is not an isolated case and neither is the general idea new. It has long been argued, for example, that moral thought about gender roles and relations must be directly informed by an understanding of the origins of any perceived psychological and behavioural differences between the sexes (e.g. Wollstonecraft 1792: ch. 2; Mill 1869: ch. 1; Dworkin 1987: ch. 7). Examples in recent academic philosophical literature include my own argument that much contemporary discussion of sexual ethics is rests on inadequate understanding of the nature of sexual desire (Webber 2009). But applied moral psychology has been sidelined over the past century as the anglophone philosophical community has emphasised the purely normative and purely conceptual aspects of the discipline. It is within this larger trend that we should situate the three-tier image of moral philosophy, which places normative thought at the centre to be applied below and clarified above.

Applied moral psychology, however, is neither an investigation of the concepts employed by normative ethical theories nor an application of those theories. In itself it has no normative dimension. It does not fit the three-tier structure. Yet we should resist any suggestion that it is not properly part of moral philosophy. The recommended approach neither denies that ethics is a normative discipline, moreover, nor tries to reduce that normativity to psychological fact. It implies no particular stand on that metaethical issue. It does not deny that psychological understanding is best pursued through the methods of empirical scientific psychology, though it should always be borne in mind that conceptual clarification is among 
those methods. What drives the approach is the idea that one proper task of moral philosophy is to view contemporary ethical issues through the lens of current empirical psychology.

\section{VII}

Philosophy in the anglophone world has been broadening its methodogical palette considerably over the past couple of decades. Although there remains a strong emphasis on conceptual and normative discussions, these seem no longer to be viewed by mainstream philosophy as its only proper occupations. The growth of cognitive science has opened up greater space for careful philosophical engagement with empirical psychology. If this continues, we should expect to see an increase in contributions to moral and political debates that draw on empirical and philosophical psychology without involving any particular normative ethical theory. This increase will help to efface the image of the three-tier structure that currently constrains ethical thought.

At the same time, increasing evidence of the problems generated by climate change is likely to make the predictions of the effects of our own current and future emissions ever more difficult to ignore. Public moral reasoning about our part in further climate change ought to continue to rise in volume and prominence. Academic philosophers should bring their expertise in moral philosophy to bear on these public debates and on public policy decisions relating to climate change. The world of applied ethics has long been dominated by medical ethics, though recent years have seen a rise in interest in issues that directly affect the majority of the population on a daily basis, such as issues in sexual ethics. As public debates about climate change increase, the environmental impact of individual behaviour and questions concerning public policy in relation to this impact ought also become more central to academic debate in applied ethics. 
If the argument of this chapter is right, moral philosophers would do well to draw directly on the empirical and philosophical psychological study of the ways in which our deeper desires and values are shaped into our more immediate motivations by the opportunities and costs that we find around ourselves, the ways in which the social world we have inherited and can alter influences our actions, hopes, and plans. Suitably translated out of the technical idiom, results of this inquiry could inform public moral reasoning about climate change, and indeed political policy formulation, in ways that help us to pursue what really matters to us without destroying the chances other people have of doing the same. 


\section{Bibliography}

Attfield, Robin. 2003. Environmental Ethics: An Overview for the Twenty First Century. London: Polity.

Crisp, Roger. 1994. Values, Reasons and the Environment. In Philosophy and the Natural Environment, edited by Robin Attfield and Andrew Belsey. Cambridge: Cambridge University Press.

Doris, John. 2002. Lack of Character: Personality and Moral Behavior. Cambridge: Cambridge University Press.

Dworkin, Andrea. 1987. Intercourse. London: Secker and Warburg.

Garvey, James. 2008. The Ethics of Climate Change. London: Continuum.

Kavka, Gregory. 1982. The Paradox of Future Individuals. Philosophy and Public Affairs 11: 93-112.

Jamieson, Dale. 2007. When Utilitarians Should Be Virtue Theorists. Utilitas 19: 160-183.

Lee, Keekok. 1994. Awe and Humility: Intrinsic Value in Nature. Beyond and Earthbound Environmental Ethics. In Pbilosophy and the Natural Environment, edited by Robin Attfield and Andrew Belsey. Cambridge: Cambridge University Press.

Lenman, James. 1999. Michael Smith and the Daleks: Reason, Morality, and Contingency. Utilitas 11: 164177.

Leopold, Aldo. 1949. The Land Ethic. In A Sand County Almanac: and Sketches Here and There, by Aldo Leopold. New York: Oxford University Press.

Light, Andrew. 2002. Contemporary Environmental Ethics: From Metaethics to Public Philosophy. Metaphilosopby 33: 426-429.

Mill, John Stuart. 1869. The Subjection of Women. London: Longmans, Green, Reader, and Dyer.

Monbiot, George. 2007. Heat. Second edition. London: Penguin. 
Mulgan, Tim. 2006. Future People: A Moderate Consequentialist Account of Our Obligations to Future Generations. Oxford: Oxford University Press.

Parfit, Derek. 1982. Future Generations: Further Problems. Philosopby and Public Affairs 11: 113-172.

Rolston, Holmes III. 1975. Is There An Ecological Ethic? Ethics 85: 93-109.

Routley, Richard. 1973. Is There A Need For A New, An Environmental, Ethic? Proceedings of the XV World Congress of Philosophy 1: 205-210.

Walker, Gabrielle, and David King. 2008. The Hot Topic: How To Tackle Global Warming and Still Keep The Lights On. London: Bloomsbury.

Webber, Jonathan. 2009. Sex. Philosophy 84: 233-250.

Webber, Jonathan. forthcoming. A Model of Character and Agency.

Williams, Bernard. 1995. Must a Concern for the Environment be Centred on Human Beings? In Making Sense of Humanity and Other Philosophical Papers, 1982-1993, by Bernard Williams. Cambridge: Cambridge University Press.

Wollstonecraft, Mary. 1792. A Vindication of the Rights of Woman: With Strictures on Political and Moral Subjects. London: Joseph Johnson. 